\title{
EJSBS
}

The European Journal of Social \&

Behavioural Science

ISSN: 2301.2218 (ONLINE)
OPENACCESS

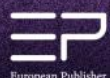

The European Journal of Social and Behavioural Sciences

EJSBS Volume XXX, Issue I (eISSN: 2301-2218)

\section{THE EFFECT OF ONLINE LEARNING ON TERTIARY LEVEL STUDENTS' MENTAL HEALTH DURING THE COVID-19 LOCKDOWN}

\author{
Ezgin Akpınar ${ }^{\text {** }}$
}

${ }^{a}$ ISO London, 34-35 D'Arblay Street, Soho, London, W1F 8EY, United Kingdom

\begin{abstract}
Covid-19 has proven to be a major disruptive aspect of human life across the world. Notably, there has been a significant shift in the normal way of life with people being required to isolate to prevent further spread of the disease. In education, the restrictions have made it imperative for the adoption of online learning. This paper highlights the effect of online learning on tertiary level students' mental health. Some of the major findings from the study include the realization that there has been an increase in mental health concerns among the students. This aspect is attributed to the isolation from peers and lecturers, the difficulty of using the online platforms, the lack of guidance and counseling, and the high levels of distractions associated with the platform. The inability to talk and interact with peers and their lecturers for instance, has proven to be a major cause of stress among this group of students. The research has shown that online learning is a major cause of stress despite being a solution to the challenges of the Covid-19 lockdown to learning.
\end{abstract}

Keywords: Covid19 lockdown, psychological stress, mental health, tertiary level students, guidance and counselling, higher education

(C) 2021 Published by European Publisher. www.europeanpublisher.com

${ }^{*}$ Corresponding author.

E-mail address: ezginakpinar01@gmail.com

doi: $10.15405 /$ ejsbs.288

This work is licensed under a Creative Commons Attribution-NonCommercial-NoDerivatives 4.0 International License. 
https://doi.org/10.15405/ejsbs.288

eISSN: 2301-2218 / Corresponding Author: Ezgin Akpinar

Selection \& Peer-review under responsibility of the Editors

\section{Introduction}

Covid-19 was first discovered in the city of Wuhan in China in 2019. As indicated by Hasan and Bao (2020), the ease of spread made it possible for the disease to spread in different parts of the world within a short time. Currently, the disease has been recorded in over 200 countries across the world. Covid-19 has proven to be the most disruptive occurrence of human life in the 21 st century. This is reflected in the manner in which the governments have been forced to introduce lockdown and travel restrictions to prevent the further spread of the disease (Prasetyaningtyas et al., 2020). The approaches taken by governments to flatten the curve have significantly affected normal life activities such as school attendance whereby students are required to complete their studies through online channels. According to Chandra (2020), up to $90 \%$ of the student population globally has been required to study at home due to the pandemic.

Mental health issues related to tertiary level students have been the subject of much research. According to Kotera et al. (2020), research has determined that the mental health of university students is generally poor with high rates of depression, anxiety and stress. This, according to them is in "itself a serious issue" but its consequences are exacerbated as it can lead to "reduced academic achievement and professional development, interpersonal conflicts, sleep disturbance, low concentration, poor decision-making, resulting feelings of inadequacy" all of which would negatively affect their learning attainment and other educational pursuits like research output (para. 4). With the forced shift to online learning platforms caused by the Covid-19 lockdown, the fears that these mental health issues would worsen are well-founded.

\section{Purpose of the Study}

The main objective of the study is to develop a script-implantation strategy in aggressive online communications in order to reduce the levels of aggression and the resentment of network communities.

\section{Research Questions}

3.1 How has the Covid-19 lockdown changed the learning environment among tertiary level students?

3.2 What are the mental health changes faced by tertiary level students during Covid19 lockdown? 
https://doi.org/10.15405/ejsbs.288

eISSN: 2301-2218 / Corresponding Author: Ezgin Akpinar

Selection \& Peer-review under responsibility of the Editors

\section{Research Methods}

The research utilizes a qualitative design whereby through a literature review approach, secondary sources with information relevant to the study title are scrutinized. The data was collected through the scrutiny of online materials from notable websites such as the Social Sciences Citation Index (SSCI). In addition, works from major platforms such as google scholar were included. The major reason for the selection of the aforementioned platforms was the need to ensure the credibility of the collected data. On the other hand, the adoption of the literature review as a research method was informed by time constraints as well as the challenges associated with implementing primary research. Ostensibly, it would have taken extensive time for the researcher to contact students from different parts of the world to acquire the necessary data regarding their perspectives on the use of online learning platforms. In this regard, therefore, the use of secondary data allowed for easy and convenient access to already available data on the topic under study. Also, a literature review is preferred when attempting to give an overview of the knowledge that has emerged globally from work done in this area as it provides a broad and extensive perspective of the issues under discussion (Synder, 2019).

\section{Findings}

Covid 19 has significantly affected the learning approaches among the tertiary level students. As highlighted by Chandra (2020), home education has generated immense disruption both among the parents and students. Although there is research that shows that online learning has been linked to increased students' ability to grasp and retain information at a faster rate, research like that of Grubic et al. (2020) however, argue that the restrictive learning conditions associated with online learning are bound to result in increased stress and downstream negative academic consequences. This assertion is based on public health studies indicating an increase in psychological issues during the pandemic. Wang et al. (2020) has reported a predominance of moderate to severe depression that is self-reported. This trend has been attributed to the prevalent effects of uncertainty as well as fears related to the health consequences of the pandemic (Brooks et al., 2020). Cao et al. (2020) substantiate the above assertions with their findings that almost $30 \%$ of the students in their study experienced anxiety as a result of the pandemic, out of which $0.9 \%$ experienced severe anxiety while the rest experienced mild anxiety. This condition seems to support the assertions that the use of online learning exacerbates mental health issues experienced by students.

The major reason given for the anxiety levels, in this case, was the concerns regarding the disruptions caused by the pandemic on their studies as well as their prospects. Hasan and Bao (2020) have found that inadequacy of the learning approach is another notable reason 
https://doi.org/10.15405/ejsbs.288

eISSN: 2301-2218 / Corresponding Author: Ezgin Akpinar

Selection \& Peer-review under responsibility of the Editors

behind increased stress levels among tertiary level students. Notably, the use of the online learning approach has exposed the learners to a wide array of challenges largely due to the lack of experience regarding its application (Rasiah et al., 2020). The effectiveness of online learning is largely dependent on the approaches adopted by learners and instructors in the implementation of the learning process (Adnan \& Anwar, 2020). As highlighted by Halupa (2016), it is highly possible that the students may be distracted when using the internet as a learning tool based on the existence of a wide array of distractions. Markedly, the existence of social media platforms has proved to be a major challenge for the youth today based on its high addiction levels. According to Hollis and Was (2016), in a survey of 129 online learners, there was a $29 \%$ risk that the participants' minds would wander off from the online learning content. This condition resulted in the students not focusing on the content being conveyed by the lecturers online. The inability to focus on the information being provided through the platform would have a subsequent impact in terms of increased stress levels among the students since they would not have understood the content delivered during the lecture and consequently, would not be able to complete their assignments according to the requirements stipulated by the lecturer. This condition seems to explain the high levels of stress and anxiety witnessed among online tertiary level learners.

Despite being the most promising alternative to traditional learning approaches, online learning has witnessed relatively negative perspectives from students. The negative perceptions, in this case, may be responsible for the psychological distress which has been identified over the recent past due to the widespread adoption of online learning. Previous studies have shown that tertiary students have developed a negative perspective due to the absence of a classroom-related environment (Dewaele et al., 2019; Khan \& Khan, 2019). Tertiary students have cited the ability to interact with their peers and instructors as being a major contributor to improved participation in learning activities. In addition to that, there have been indications of online crack-up impeding effective utilization of the learning platforms. Some of the notable reasons for e-learning crack-up include lack of hardware support, and software incompatibility (Aboagye et al., 2020). These conditions have resulted in students experiencing numerous challenges in the online learning environment, an aspect which they would have never experienced in the traditional environment. Bolatov et al. (2020) have found that while online learning seemed to produce a reduction in stress among students related to the completion of their course content, this benefit however, seems to fade when interpersonal stress was evaluated. Essentially, the study showed that students using online learning were experiencing peer-related burnout, an aspect which was linked to the inability of the students connect on a personal level with their peers (Radha et al., 2020). This study showed the 
https://doi.org/10.15405/ejsbs.288

eISSN: 2301-2218 / Corresponding Author: Ezgin Akpinar

Selection \& Peer-review under responsibility of the Editors

existence of a strong correlation between the use of online learning and psychological stress among the students.

The lack of support from the government and other stakeholders is another aspect that can increase psychological stress among tertiary students. A number of developing countries have not fully embraced the use of online learning as an alternative to traditional learning approaches (Dhawan, 2020), contributing to e-learning crack-up. The reasons for this will be further explored later on in the discussion. According to the survey by Lee (2020a) more than $80 \%$ of students surveyed experienced psychological stress due to e-learning crack-up while a further, $26 \%$ suffered from the lack of guidance and counseling. Unlike the traditional form of learning, the online learning approach is devoid of the guidance associated with counseling which has always been integral for the handling of psychological and emotional issues among students in at all educational levels (Elsalem et al., 2020). The lack of counseling and other forms of guidance, in this case, implies that the stress and other challenges experienced by the students end up not being addressed; an aspect that will proved detrimental in the long term to students' mental health.

Students' negative perceptions towards the online learning platforms have also been exacerbated by the lack of infrastructure which can provide equal access to learners. Beaunoyer et al. (2020) postulate that students from wealthy homes would naturally have access to better internet and computer devices, an aspect which places them at a vantage point of embracing the online learning experience more fully. Unfortunately, students from financially disadvantaged families will experience challenges getting access to the internet and even the basic devices in order to participate satisfactorily in online learning (Al-Balas et al., 2020). To illustrate this with actual examples, there have been cases in certain countries which experience significant digital divide, that tertiary level students had to resort to climbing up trees and setting up camps on hilltops in order to get better connectivity to enable them to take their examinations (Lee, 2020b). Having to take an exam is already a stressful situation, but having to take an exam on top of a tree or in a camp in the middle of a jungle must have been a psychological nightmare for these students. One can only imagine the difference in the psychological stress of students in such conditions and those who are comfortably seated in their air-conditioned rooms in their houses with no worries about connectivity let alone falling out of the tree or being pounced on by a predator in the jungle. Thus, it can be assumed that online learning is not providing tertiary level students and even younger students with a level playing field in terms of accessibility. 
Education is presumed to be a great equaliser for young people in terms of opening up opportunities for their future. However, the presence of such variations caused by the digital divide, in this case, would have definitely resulted in the development of negative perspectives towards online learning due to its discriminative nature (Karuppannan \& Mohammed, 2020). Such difficult circumstances would have contributed to psychological stress and anxiety, and subsequent reduction in effective utilization of the online learning platforms. This condition is further worsened by the fact that a large number of students, especially those from developing countries, come from financially disadvantaged families. Online learning does not come cheap; a laptop and internet connectivity are prerequisites that must be in place before online learning can proceed. Most financially disadvantaged families usually have more than one child which means that, at any one time, several children at different stages of learning would need a laptop each to be engaged with their teachers online. This raises the question of whether a poor family with many children can afford such a financial outlay to educate all their children. Even a financially average family with three to four children would be faced with considerable financial outlay in order to ensure that all the children are equipped with the devices and the connectivity to meet online learning requirements. engaging in online learning. Even a basic laptop costs a considerable sum of money plus the payment for connectivity would all add up for a family that is struggling with finances. On top of that, with the current economic situation, many have lost their jobs and are struggling to make ends meet. Parents in such circumstances would be hard pressed to equip their children with the necessary technological access to participate in online learning. We do not need to undertake research to understand the impact of such inequity on the psychological well-being and educational progress of learners unfortunate enough to be in such circumstances.

It goes without saying then that a disproportionately large number of students worldwide are facing a severe educational disruption because they simply do not have the resources for proper utilization of online learning. In terms of their educational development, this is grossly unfair to the children and, in particular tertiary level students as they are so close to embarking on their professional journey.

Studies have also established a strong correlation between poverty and stress (Kokosi et al., 2020). This condition seems to suggest that those living in poverty in this regard are likely to have direct contact with the difficult living conditions associated with the poverty levels in their families. Baticulon et al. (2020) further suggest that the major obstacles experienced by students from poor families include technology, support, family, and personal aspects. The study also revealed that only $41 \%$ of the tertiary students believed that they could participate satisfactorily in online learning both physically and mentally (Baticulon et al., 
https://doi.org/10.15405/ejsbs.288

eISSN: 2301-2218 / Corresponding Author: Ezgin Akpinar

Selection \& Peer-review under responsibility of the Editors

2020). The aforementioned reasons seem to echo the fact that most students fear the loss of an academic year through engagement in online learning. In essence, the fear of losing an academic year combined with the challenges of accessing the necessary technology has served to exacerbate the psychological distress being experienced by students of all levels, but particularly at tertiary level, the distress would be more worrying as these students would naturally be concerned about the effect on their job prospects.

\section{Conclusion}

Despite proving to be the most effective alternative to traditional learning during this lockdown, online learning has been acknowledged to be a major source of mental health issues among tertiary level students. As shown in the analysis, the lack of interaction with peers, for instance, is a significant aspect that has affected the ability of the students to experience the optimal benefits of online learning. It is undeniable that the ability to interact with peers and the instructor in the traditional classroom environment cannot be replicated in an online environment despite the offerings of interactive platforms like zoom, skype and google meet. Kalenzi et al. (2020) in their article in the World Economic Forum hit the nail on the head when they state that "it's clear that some aspects of college education, including learning with peers and interactions with professors, the campus dormitory life and college games, cannot be "Zoomed"' (para. 5). While these may be satisfactory platforms of interaction for adults, younger adults like tertiary level students, who are still in their developmental stage, are still largely psychologically, emotionally and socially dependent on face-to-face interpersonal relationships with their peers and instructors to transform their learning experience into a productive and happy one. Learning, after all, is not only about the acquisition of hard skills. Soft skills, developed through the campus experience of working together in co-curricular activities, class projects or just chatting with classmates, also contribute immensely to the development of the students at any stage of learning.

In this case, the abrupt and 'forcible' removal from such an environment would have resulted in increased stress and anxiety among the students. In addition to that, as stated earlier, the high levels of distractions associated with the online learning platforms have been shown to impact the ability of the students to concentrate and retain the learning content. Online learning is by default an isolated and isolating experience. One is, for all intents and purposes, alone, looking at the screen, listening to the instructor or attempting some exercise. It is so easy to lose focus, start checking the social media or even play games because, unlike the traditional classroom, no one is there to check on you. This kind of learning environment may suit introverts or unsociable people but it would take a heavy toll mentally on extroverts and 
https://doi.org/10.15405/ejsbs.288

eISSN: 2301-2218 / Corresponding Author: Ezgin Akpinar

Selection \& Peer-review under responsibility of the Editors

sociable young people. If adults have reported becoming depressed by working from home, what more young people?

Subsequently, the loss of focus has been linked to increased stress due to the inability to effectively grasp the course content. The use of the online platform is also devoid of normal stress handling mechanisms such as counselling and/or guidance provided by instructors which would be immediate in a traditional classroom based on perceiving the body language cues of the students. In the asynchronous online environment, there is no way for lecturers to know if their students are focusing on the content or slacking or if they understand the content through body language cues, unless it is a very small class and videos can be switched on for the duration of the class. The corresponding author of this paper is a lecturer in a tertiary institution who has been teaching online since the start of the lockdown in March this year, has much anecdotal evidence to offer on the issue of interaction using online platforms. Questions like "Do you understand the content so far?" or "Does anyone have any questions?" are usually met with two responses: complete silence or a few "yes" appearing in the chatbox. Calling out students on an individual basis may elicit some form of response but, on the whole, there is "something" missing in the interaction. Even when offered personal consultation time, very few students take advantage of it. In this case, the "distance" in the term distance learning seems to be the operative word.

Finally, the inability to acquire the necessary learning tools and resources has been determined to directly affect the learning process using online platforms. This condition is directly attributed to the variations in income and ability to afford computers and internet connections necessary for fully embracing online learning. It is highly likely that any one or a combination of all these factors would lead students to experience heightened levels of stress and anxiety which would affect their mental health and ultimately their learning progress and professional development.

In general, while online learning can be considered a lifesaver in terms of sustaining educational continuity during the lockdown, it has nevertheless, its fair share of deterrents that have proved to be a major source of mental health issues among tertiary level students. The implications of this are both wide and deep as we are looking at a group of people who are just starting out in life but who are already mentally fractured brought on by the very system that should be affirming their mental capacities to be productive human capital and citizens, and happy, fulfilled human beings. The Covid19 lockdown has taught us many valuable lessons and for those in education, one lesson is that it is high time for governments and concerned stakeholders to acknowledge that online learning is not without its drawbacks. A concerted 
https://doi.org/10.15405/ejsbs.288

eISSN: 2301-2218 / Corresponding Author: Ezgin Akpinar

Selection \& Peer-review under responsibility of the Editors

effort must be made to ensure that this valuable learning alternative is equally accessible for all learners and that it is implemented in such a way as to optimise learning.

\section{Acknowledgements}

The author(s) declare that there is no conflict of interest.

\section{References}

Aboagye, E., Yawson, J. A., \& Appiah, K. N. (2020). COVID-19 and E-learning: The challenges of students in tertiary institutions. Social Education Research, 2(1), 1-8. https://doi.org/10.37256/ser.212021422

Adnan, M., \& Anwar, K. (2020). Online Learning amid the COVID-19 Pandemic: Students' Perspectives. Journal of Pedagogical Sociology and Psychology, 2(1), 45-51. https://doi.org/10.33902/JPSP.2020261309

Al-Balas, M., Al-Balas, H. I., Jaber, H. M., Obeidat, K., Al-Balas, H., Aborajooh, E. A., \& AlTaher, R. (2020). Distance learning in clinical medical education amid COVID-19 pandemic in Jordan: current situation, challenges, and perspectives. BMC medical education, 20(1), 1-7. https://doi.org/10.1186/s12909-020-02257-4

Baticulon, R. E., Alberto, N. R. I., Baron, M. B. C., Mabulay, R. E. C., Rizada, L. G. T., Sy, J. J., Tiu, C. J. S., Clarion, C. A., \& Reyes, J. C. B. (2020). Barriers to online learning in the time of COVID-19: A national survey of medical students in the Philippines. [preprint]. medRxiv. https://doi.org/10.1101/2020.07.16.20155747

Beaunoyer, E., Dupéré, S., \& Guitton, M. J. (2020). COVID-19 and digital inequalities: Reciprocal impacts and mitigation strategies. Computers in Human Behavior, 106424. https://doi.org/10.1016/j.chb.2020.106424

Bolatov, A. K., Seisembekov, T. Z., Askarova, A. Z., Baikanova, R. K., Smailova, D. S., \& Fabbro, E. (2020). Online-Learning due to COVID-19 Improved Mental Health Among Medical Students. Medical science educator, 1-10. https://doi.org/10.1007/s40670020-01165-y

Brooks, S. K., Webster, R. K., Smith, L. E., Woodland, L., Wessely, S., Greenberg, N., \& Rubin, G. J. (2020). The psychological impact of quarantine and how to reduce it: rapid review of the evidence. The Lancet, 395, 912-920. https://doi.org/10.1016/S01406736(20)30460-8

Cao, W., Fang, Z., Hou, G., Han, M., Xu, X., Dong, J., \& Zheng, J. (2020). The psychological impact of the COVID-19 epidemic on college students in China. Psychiatry research, 112934. https://doi.org/10.1016/j.psychres.2020.112934

Chandra, Y. (2020). Online education during COVID-19: perception of academic stress and emotional intelligence coping strategies among college students. Asian Education and Development Studies. https://doi.org/10.1108/AEDS-05-2020-0097

Dewaele, J. M., Magdalena, A. F., \& Saito, K. (2019). The effect of perception of teacher characteristics on Spanish EFL Learners' Anxiety and Enjoyment. The Modern Language Journal, 103(2), 412-427. https://doi.org/10.1111/modl.12555 
Dhawan, S. (2020). Online learning: A panacea in the time of COVID-19 crisis. Journal of Educational Technology Systems, 49(1), $5-22$. https://doi.org/10.1177/0047239520934018

Elsalem, L., Al-Azzam, N., Jum'ah, A. A., Obeidat, N., Sindiani, A. M., \& Kheirallah, K. A. (2020). Stress and behavioral changes with remote E-exams during the Covid-19 pandemic: A cross-sectional study among undergraduates of medical sciences. Annals of Medicine and Surgery, 60, 271-279. https://doi.org/10.1016/j.amsu.2020.10.058

Grubic, N., Badovinac, S., \& Johri, A. M. (2020). Student mental health in the midst of the COVID-19 pandemic: A call for further research and immediate solutions. International Journal of Social Psychiatry, 0020764020925108. https://doi.org/10.1177/0020764020925108

Halupa, C. (2016). Risks: The Impact of Online Learning and Technology on Student Physical, Mental, Emotional, And Social Health. In International Conference of Education, Research and Innovation (pp. 6305-6314). Seville, Madrid. https://doi.org/10.21125/iceri.2016.0044

Hasan, N., \& Bao, Y. (2020). Impact of "e-Learning crack-up" perception on psychological distress among college students during COVID-19 pandemic: A mediating role of "fear of academic year loss". Children and Youth Services Review, 118, 105355. https://doi.org/10.1016/j.childyouth.2020.105355

Hollis, R. B., \& Was, C. A. (2016). Mind wandering, control failures, and social media distractions in online learning. Learning and Instruction, 42, 104-112. https://doi.org/10.1016/j.learninstruc.2016.01.007

Kalenzi, C., Back, D., \& Yim, M. (2020, November 13). The Future of Online Education: Lessons from South Korea. World Economic Forum. https://www.weforum.org/agenda/2020/11/ lessons-from-south-korea-on-the-futureof-online-education/

Karuppannan, S., \& Mohammed, L. A. (2020). Predictive Factors Associated with Online Learning during Covid-19 Pandemic in Malaysia: A conceptual Framework. International Journal of Management and Human Science (IJMHS), 4(4), 19-29. https://ejournal.lucp.net/index.php/ ijmhs/article/download/1236/1300

Khan, S., \& Khan, R. A. (2019). Online assessments: Exploring perspectives of university students. Education and Information Technologies, 24, 661-677. https://doi.org/10.1007/s10639-018-9797-0

Kokosi, T., Flouri, E., \& Midouhas, E. (2020). The role of inflammation in the association between poverty and working memory in childhood. Psychoneuroendocrinology, 123, 105040. https://doi.org/10.1016/j.psyneuen.2020.105040

Kotera, Y., Ting, S. H., \& Neary, S. (2020). Mental health of Malaysian university students: UK comparison, and relationship between negative mental health attitudes, selfcompassion, and resilience. Higher Education. https://doi.org/10.1007/s10734-02000547-w

Lee, J. (2020a). Mental health effects of school closures during COVID-19. The Lancet Child \& Adolescent Health, 4(6), 421. https://doi.org/10.1016/S2352-4642(20)30109-7

Lee, S. (2020, June 16). Sabah student stays overnight in tree to get better Internet connection for online university exams. The Star. https://www.thestar.com.my/news/nation/2020/06/16/ sabah-uni-student-staysovernight-in-tree-to-get-better-internet-connection-for-online-exams 
Prasetyaningtyas, W. E., Nasri, W. O. L. A., \& Amalianita, B. (2020). Self-report on the occurrence of insomnia and the habit of taking multivitamins against academic stress among students in the early period of COVID-19 pandemic. Konselor, 9(2), 81-94. https://doi.org/10.24036/0202092110553-0-00

Radha, R., Mahalakshmi, K., Kumar, V. S., \& Saravanakumar, A. R. (2020). E-Learning during lockdown of covid-19 pandemic: a global perspective. International journal of control and automation, 13(4), 1088-1099. https://doi.org/10.1509/jm.16.0250

Rasiah, R., Kaur, H., \& Guptan, V. (2020). Business Continuity Plan in the Higher Education Industry: University Students' Perceptions of the Effectiveness of Academic Continuity Plans during Covid-19 Pandemic. Applied System Innovation,3(4), 51. https://doi.org/10.3390/asi3040051

Synder, H. (2019). Literature review as a research methodology: An overview and guidelines. Journal of Business Research 104, 333-339. https://doi.org/10.1016/j.jbusres.2019.07.039

Wang, C., Pan, R., Wan, X., Tan, Y., Xu, L., Ho, C. S., \& Ho, R. C. (2020). Immediate psychological responses and associated factors during the initial stage of the 2019 coronavirus disease (COVID-19) epidemic among the general population in China. International journal of environmental research and public health, 17(5), 1729. https://doi.org/10.3390/ijerph17051729 